\title{
Editorial
}

\section{Editorial from the Editor-in-Chief to Introduce the Journal}

\author{
Wendy M. Purcell (D)
}

check for updates

Citation: Purcell, W.M. Editorial from the Editor-in-Chief to Introduce the Journal. Merits 2021, 1, 3-4. https://doi.org/10.3390/merits1010002

Received: 11 May 2021

Accepted: 11 May 2021

Published: 18 May 2021

Publisher's Note: MDPI stays neutral with regard to jurisdictional claims in published maps and institutional affiliations.

Copyright: (C) 2021 by the author. Licensee MDPI, Basel, Switzerland. This article is an open access article distributed under the terms and conditions of the Creative Commons Attribution (CC BY) license (https:// creativecommons.org/licenses/by/ $4.0 /)$.
Harvard T.H. Chan School of Public Health, Harvard University, Boston, MA 02215, USA; wpurcell@hsph.harvard.edu

People at work is the focus of Merits, an international, peer-reviewed open access journal. We focus on contemporary research issues related to enabling people at work to thrive. Aligned through purpose, vision and values, people are the real drivers of change. They are our most important resource at work and their collective efforts fuel the global economy. Faced with a myriad of societal challenges, people in work within organizations, institutions, in multi-actor collaborative networks and entrepreneurial settings are striving to create a world that rebalances prosperity with planet. The future is "human-led and human-centered" [1].

Merits seeks to go beyond traditional constructs of human resources and offer insights into work-based strategies to advance employee engagement, creativity and productivity. Given the global focus on talent, we want to examine how equity, belonging and inclusion are championed alongside well-being and innovation. This is especially important given the multi-generational workforce and a worldwide awakening around social justice. As people at work reacted and then responded to the COVID-19 pandemic, we are now focused on reimagining work and workplaces [2]. With any crisis presenting both danger and opportunity, people improvised in the moment but with a view on shaping the new order. The future of people at work will demand bold persistent experimentation, alongside radical collaboration.

Merits recognizes the importance of investing in human performance, so includes exploration of talent development modalities and frameworks, people analytics, and issues related to coaching and mentoring. With value creation nested in teams, we are interested in collective efforts to advance co-creative endeavors. We also want to see how the development of employability is advanced through education and experiential learning, given the significant demand for upskilling throughout life [3]. Means to enable people to navigate these times, defined by high degrees of volatility, uncertainty, complexity and ambiguity, invite us to explore resilience and adaptability. We recognize that in exploring people at work, there may be a need to emphasize social justice, community and relationship building more, and foster collaboration and the contribution that people can make to solving global problems.

Merits curates and shares leading-edge research in the field relevant to high-impact practices, thereby enabling the translation of knowledge to support the optimal performance of people at work. We invite your contribution to the field.

\section{Conflicts of Interest}

The author declares no conflict of interest. 


\section{References}

1. Boland, B.; De Smet, A.; Palter, R.; Sanghvi, A. Reimagining the Office and Work Life after COVID-19. Available online: https: //www.mckinsey.com/ \{\}/media/McKinsey/Business\%20Functions/Organization/Our\%20Insights/Reimagining\%20the\% 20office\%20and\%20work\%20life\%20after\%20COVID\%2019/Reimagining-the-office-and-work-life-after-COVID-19-final.pdf (accessed on 9 May 2021).

2. Schwab, K.; Davis, N. Shaping the Future of the Fourth Industrial Revolution. Available online: https://www.pearl-hifi.com/11 _Spirited_Growth/10_Health_Neg/09_Facism/Schwab_and_the_The_Fourth_Industrial_Revolution/Schwab_Shaping_the_ Future_of_the_Fourth_Industrial_Revolution.pdf (accessed on 9 May 2021).

3. Purcell, W.M.; Lumbreras, J. Higher Education and the COVID-19 Pandemic: Navigating Disruption using the Sustainable Development Goals. Discov. Sustain. 2021, 2, 1-16. [CrossRef]

\section{Short Biography of Editor-in-Chief}

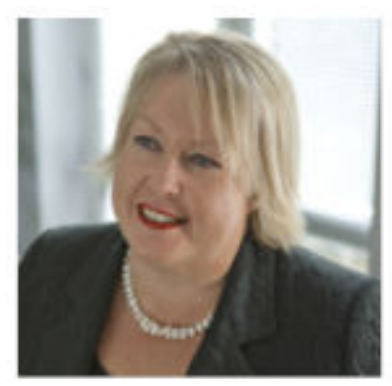

Wendy M. Purcell, PhD FRSA (pronouns: she, her, hers), Harvard T.H. Chan School of Public Health, Harvard University. Leads research on global leadership and governance for sustainable transformation in various business sectors and higher education and directs the Sustainable Development Solutions Group. Wendy is Emeritus Professor and President Vice-Chancellor Emerita (UK university, 2007-2015), taking it to the top 1\% of world universities. Former Non-Executive Director to the UK Government's Department of Business, Innovation and Skills and Chair of its Nominations (Talent) Committee, she advises Cabinet Office on talent and diversity. Expert Adviser and Board member to a range of global Boards and charities and registered Coach. wpurcell@hsph.harvard.edu https://scholar.harvard.edu/wendypurcell;

https:/ / connects.catalyst.harvard.edu/Profiles/display/Person/152606 